\title{
Effect of Garcinia Imberti Bourd Against Candida Isolates in Rootcanal Infection
}

\author{
Srikrishnan Rajendran Sri Ramkumar' , Natesan Sivakumar²*, Jaya Balaji Mano Christaine Angelo \\ 'Department of Microbiology, Bharathiyar University, Tamilnadu, INDIA. \\ 2Department of Molecular Microbiology, Madurai Kamaraj University, Tamilnadu, INDIA. \\ ${ }^{3}$ Department of Conservative Dentistry and Endodontics, Sree Mookambika institute of Dental science Kulasekharam, Tamilnadu, INDIA.
}

\begin{abstract}
Background: Many research works are being carried out in preparing intracanal medicaments using herbal plants since it is safe as well as containing a better therapeutic value. The present study was designed to evaluate the anticandidal properties of the leaves of Garcinia imberti bourd in associated with the root canal infection. Method: Totally 94 root canal infected samples were collected and their previous history also recorded. Samples yielded Candida isolates were screened through drug resistant study. Multi drug-resistant Candida albicans was isolated and characterized by $18 \mathrm{~S}$ rDNA sequencing. An antifungal activity of the extracts of the leaves of G.imberti bourd was performed by disc diffusion method. Using Silica-60 column active fraction of the methanol extract was partially purified and was analyzed by Gas Chromatography-Mass Spectrophotometry (GC-MS). Prepare intracanal medicament with methanol extract of G.imberti bourd and was tested with multidrug-resistant C.albicans (Ca-09) under in-vitro conditions using decoronated teeth. Efficacy also compared with chlorohexidine. Result: A total of 48 Candida sp. were isolated and screened for antibiotic susceptible test. Among them isolate $\mathrm{Ca}-09$ showed multiple antibiotic resistant. Crude methanol fraction of $G$. imberti bourd leaf extract,
\end{abstract}

as well as the partially purified compound of this extract, showed better anticandidal activity. $0.01 \mathrm{~g}$ of methanol extract with $2 \%$ methyl cellulose gel showed significant reduction (63\%) of C.albicans in in-vitro intracanal treatment. Conclusion: Methanol extract of Garcinia imberti bourd leaf contains glycerine, which can be used in preparing the suitable intracanal medicament for the treatment of root canal infection.

Key words: Candida albicans, Chlorohexidine, Garcinia imberti bourd, Glycerine, Intracanal medicament, Root canal infection.

\section{Correspondence :}

Dr. N. Sivakumar, Department of Molecular Microbiology, Madurai Kamaraj University, Tamilnadu, INDIA.

Phone no: 919445389174

Email: microshivaak@yahoo.co.in

DOI: 10.5530/jyp.2017.9.42

\section{INTRODUCTION}

Root canal infection is the most significant oral health problem, and it develops due to the presence of microbial communities within the root canal. ${ }^{1}$ As the root canal system act as reservoir ${ }^{2}$ which results in a death of dental pulp, this may occur due to dental caries thermal damage, mechanical trauma tooth wear from grinding and micro leakage of dental restoration or tooth fracture. ${ }^{3}$ Usually, these are favoring to facilitate the growth of opportunistic pathogens like Candida albicans, C. tropicalis and C. dubliniensis. ${ }^{4}$ These species are primarily influencing the oral bacterial diversity as well antibiotic resistance. Although Candida species are sensitive to intracanal medicaments, their virulence factor enables them to adhere and penetrate into the root canal. ${ }^{5}$ Sometimes the growth of the microorganism is enhanced by procedural errors of experts during treatment. ${ }^{2}$ An aim of the treatment is to prevent the infection as well as the side effects resulted from the irrigants, $\mathrm{NaOCl}$, chlorohexidine (CHX) and calcium hydroxide. ${ }^{6}$ As the solutions applied in intracanal medicaments often causing toxicity, tissue necrosis and reducing the hardness and structural stability of the dentin within the root canal. ${ }^{7}$ Many research works are being carried out to focus the treatment using herbal extracts. ${ }^{8}$ In this series, the present study was conducted to evaluate the inhibitory effect of leaves of Garcinia imberti bourd towards the species of Candida isolated from root canal infection.

\section{MATERIALS AND METHODS}

Infected root canal samples were collected from local Dental hospitals of Kanyakumari district after getting the ethical clearance from the ethical committee, Govt. medical college, Kanyakumari District, Tami Nadu, India. By using the dried paper points samples were drawn from the root canal infected cases. ${ }^{9}$ Simultaneously their clinical history was also noted.

\section{Culturing and Identification of Isolates}

Transfer the samples into Amies transport medium and were brought into the laboratory within a hour. For the isolation, it was streaked primarily on Sabouraud's Dextrose Agar (SDA), after confirming the growth; the colonies were differentiated by streaking it over the Hichrom Candida differential agar. Morphologically distinct colonies were identified by the biochemical test as well as Germ tube test. Then the isolates were subjected to antifungal sensitive assay with standard disc diffusion method using Himedia disc such as, fluconazole (10 mcg), ketoconazole (10 mcg), itaconazole (30 mcg) and amphotericin B (100 Units).

\section{Collection of plant materials}

Leaves of Garcinia imberti bourd (local name: Mania Kanji) were collected from Ponmudi forest, Kerala, India and was identified by Dr. Ramasubbu, Department of Biology, Gandhigram University, Dindigul. The voucher specimen was stored in the same department. Leaves were dried under the shadow and then powdered. 


\section{Preparation of crude extract}

$30 \mathrm{~g}$ of the dried leaf powder was extracted with $300 \mathrm{ml}$ of Hexane in Soxhlet apparatus. ${ }^{10}$ After 12 hours, Hexane was evaporated by using rotary evaporator at $40^{\circ} \mathrm{C}$. Similar procedure was performed to prepare methanol, ethyl acetate, and petroleum ether extracts. Eventually, the portion of the extracts was stored in DMSO $(1 \mathrm{~g} / \mathrm{ml})$ for further use. ${ }^{4}$

\section{Anticandidal activity}

Disc diffusion method was performed to screen anticandidal activity. $50 \mu \mathrm{l}$ of different Candida isolates were swabbed over the SDA agar. Discs with $2.0 \mathrm{mg}$ concentrations of various crude extracts of G.imberti bourd were placed. Plates were incubated at $37^{\circ} \mathrm{C}$ for 2 days. After incubation, the inhibitory zone was measured and recorded.

\section{Column chromatography}

Crude methanol extracts were subjected into the scheme of column chromatography using silica gel (60-120 mesh) and were eluted with the solvent such as chloroform, ethyl acetate and methanol (100:0, 90:10, $80: 20,70: 30,60: 40 \ldots 0: 100) .{ }^{11}$ After that, the active fraction was subjected into Thin Layer Chromatography (Preparative -TLC) and their activity was evaluated.

\section{Gas Chromatography - Mass Spectrophotometry (GC-MS) analysis}

The active fraction F21 was analyzed by GC-MS method. ${ }^{12}$ In this, initial temperature programmed for the oven was from $60^{\circ} \mathrm{C}(2 \mathrm{~min})$ to $300^{\circ} \mathrm{C}$ for $6 \mathrm{~min}$, samples to be injected in the split mode with the ratio of 10:1 percentage, and the active constituents of the extract was expressed as a percentage by peak area.

\section{In-vitro intracanal medicament efficacy of plant extracts against $C$. albicans using decoronated teeth}

Freshly extracted thirty single-rooted mandibular premolar teeth were taken. Teeth were decoronated using the diamond disc at the level of CEJ. Canals with the size of F3 were made using the protaper NiTi system. Teeth were irrigated with $5.25 \% \mathrm{NaOCl}$ and EDTA for $5 \mathrm{~min}$ and then rinsed with physiological saline $(0.9 \% \mathrm{NaCl})$. The outer surface of the root was coated with two coats of nail varnish. Apical foramen sealed with type- 2 glass ionomer cement and the teeth were transferred to sterile glass tubes. After autoclaving the tubes containing roots were infected with C. albicans $(\mathrm{Ca}-09)$ at $10^{3} \mathrm{CFU} / \mathrm{ml}$ and incubated the tubes at $37^{\circ} \mathrm{C}$ for 21 days, every three days, it was replenished with fresh C. albicans Ca-09. The experiment was performed with three different groups. In group-I, normal saline with one gram of $2 \%$ methyl cellulose was used as an intracanal medicament. In group-II, $0.01 \mathrm{~g}$ of a methanol extract with $2 \%$ methyl cellulose was applied. In group-III, $20 \mu \mathrm{l}$ of $2 \%$ chlorohexidine with $2 \%$ methyl cellulose combination was employed. Finally, the canals were irrigated, and dentinal shavings were made by using paesoreamer size No 4 . Aliquots of saline along with dentinal shavings were drawn from the root canal and plated on SDA. After incubation, the growth of C. albicans and the anti-candida activity were measured. ${ }^{13}$

\section{RESULTS AND DISCUSSION}

Out of 94 samples, Candida spp. resulted from 48 patients (51.06\%), from which $58.33 \%$ C. albicans $(\mathrm{n}=28), 27.08 \%$ C. tropicalis $(\mathrm{n}=13)$ and $14.6 \%$ C. krusei ( $\mathrm{n}=7$ ) (Table 1). Among these, 4 isolates (14.28) out of 28 C.albicans was yielded from the patient with diabetes. It seems that the root canal infection is commonly associated with diabetes. In a diabetic patient, glucose provides the carbon source for the betterment of the growth of $C$. albicans. This finding was almost compatible with the previous study results. ${ }^{14,15}$ isolated Candida albicans in root canals of teeth with apical periodontitis. The growth of C. albicans on Hichrome Candida differential agar was examined (Figure 1a) and the microscopic examination of C. albicans has been appeared in blue colour with lactophenol cotton blue staining (Figure 1b). This study showed that there was no Candida species yielded from patients who have been affected by the urinary tract infection and cardiac infection. Hence those cases were not focused in this study. In terms of the resistance study, all the isolates were analyzed with the agents like Fluconazole, Ketoconazole, Itaconazole and Amphotericin B (Figure 1c). In the present study, single drug resistance were observed in four C. albicans strains isolated from diabetic endodontic cases, whereas strain $\mathrm{Ca}-09$ alone shows multidrug resistance. It might be due to the patients could have received the repeated course of antifungal medication. ${ }^{16,17}$ Remaining all other Candida isolates were found to be sensitive to above antifungal agents. Secluded multidrug resistance isolate (Ca-09) was further characterized by $18 \mathrm{~S}$ rDNA sequencing study and also reported (Figure 1d), it was 99\% sequence similar to C. albicans (gi-347810985). ${ }^{18}$ identified C. albicans from dental biofilm, however, ${ }^{19}$ used species specific DNA probes for rapid identification of Candida species.

Anticandidal activity of the leaves of Garcinia imberti bourd was performed with solvents like methanol, ethyl acetate, petroleum ether, and hexane. However, highest anti-candidal activity has resulted from the methanol extract $(21 \mathrm{~mm} ; 2 \mathrm{mg} / \mathrm{disc})$. It is due to the active constituents of leaves could have been eluted with methanol (Figure 2). However, the hexane extract showed the less inhibitory zone $(<7 \mathrm{~mm})$ and the moderate inhibitory zone $(17 \mathrm{~mm})$ resulted from the ethyl acetate extract. Usually, the members of Garcinia species were found to be potentially active against Candida albicans. ${ }^{20}$ The methanolic extract of Garcinia indica had been reported to have specific inhibition towards C. albicans. ${ }^{21}$ The results of the present study are approximately similar with the report, which has been showed by the previous study. ${ }^{22}$ Interestingly, the preparation of crude extract of Garcinia using methanol seems to be good activity against $C$. albicans. Comparatively, inhibition towards the $C$. albicans was relatively high when the isolate has been tested with partially purified compound ( $10 \mu \mathrm{g} / \mathrm{ml}: 26 \mathrm{~mm})$, which could have been achieved by the presence of active compounds. The active compounds of the F21 fraction eluted through Silica column (60-120 mesh size) was further characterized by GC-MS method (Figure 3), which shows the compounds such as, Decozene, 3,7,11,15 tetra methyl-12- Hexa decen 1-01, 3 Butoxy 1,1,1,5.5,5-hexa methyl 3-(trimethyl siloxy) trisilloxane (Table 2). Apart from this, Glycerine was also identified in the sample, since this can be recommended as active ingredients in making herbal intracanal medicament. ${ }^{23}$

According to in-vitro study, saline $(0.9 \% \mathrm{NaCl})$ with $2 \%$ methyl cellulose could be used as the control ${ }^{13}$. The activities of methanolic extract of G. imberti bourd and control intracanal medicament $\mathrm{CHX}$ were evaluated after irrigation. The results were reported as colony forming unit

\begin{tabular}{|c|c|c|c|c|c|c|c|}
\hline \multirow{2}{*}{$\begin{array}{l}\text { Isolates } \\
(n=94)\end{array}$} & \multirow{2}{*}{$\begin{array}{c}\% \text { of } \\
\text { Positive }\end{array}$} & \multicolumn{4}{|c|}{ Clinical history } & \multicolumn{2}{|c|}{$\begin{array}{c}\text { Drug } \\
\text { Resistance }\end{array}$} \\
\hline & & Diabetic & Cardiac & UTI & RTI & $\begin{array}{l}\text { Single } \\
\text { drug }\end{array}$ & $\begin{array}{l}\text { Multi } \\
\text { drug }\end{array}$ \\
\hline $\begin{array}{c}\text { C. } \\
\text { albicans }\end{array}$ & $\begin{array}{c}29.78 \\
(n=28)\end{array}$ & $4(14.28)$ & - & - & - & 4 & 1 \\
\hline $\begin{array}{c}\text { C. } \\
\text { tropicals }\end{array}$ & $\begin{array}{c}13.82 \\
(n=13)\end{array}$ & - & - & - & - & - & - \\
\hline C. krusei & $\begin{array}{c}7.44 \\
(n=7)\end{array}$ & - & - & - & - & - & - \\
\hline
\end{tabular}

UTI - Urinary tract infection; RTI - Respiratory tract infection 

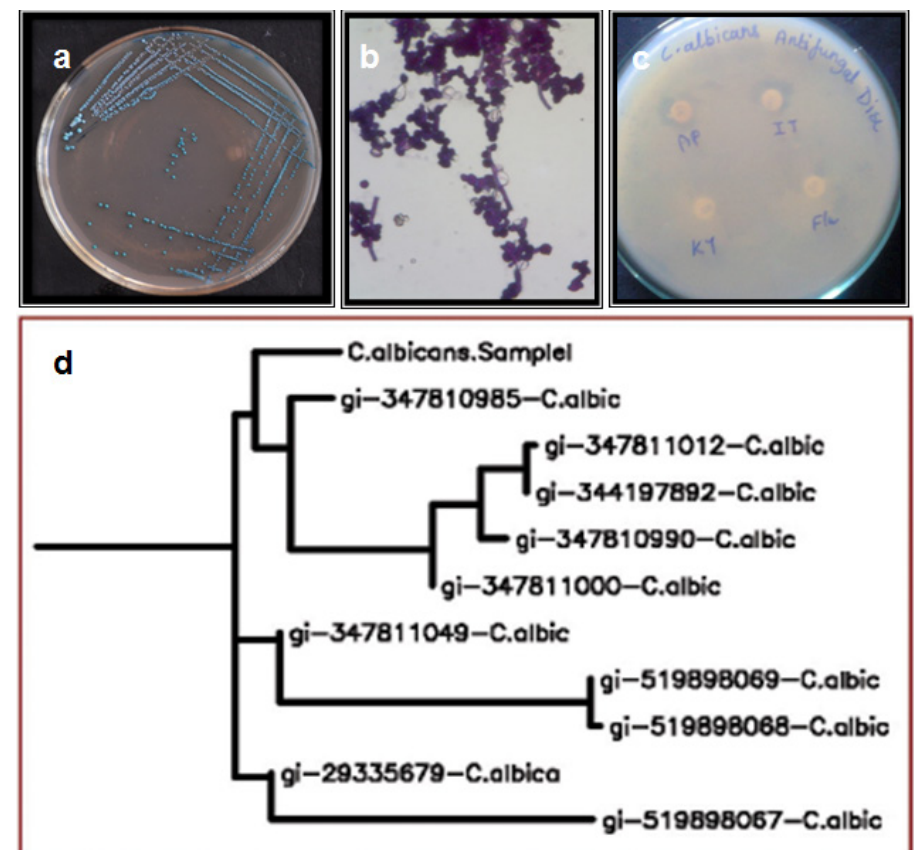

Figure 1: Characterization of drug-resistant Candida albicans from the root canal infected sample. a) C. albicans (Ca-09) growth on Sabouraud's Dextrose Agar, b) microscopic image of C. albicans (Ca-09) after lactophenol cotton blue (100 X), c) drug resistant analysis of C. albicans (Ca-09) against antifungal drugs (Himedia-disc), d) Phylogenetic tree of C. albicans (Ca-09).
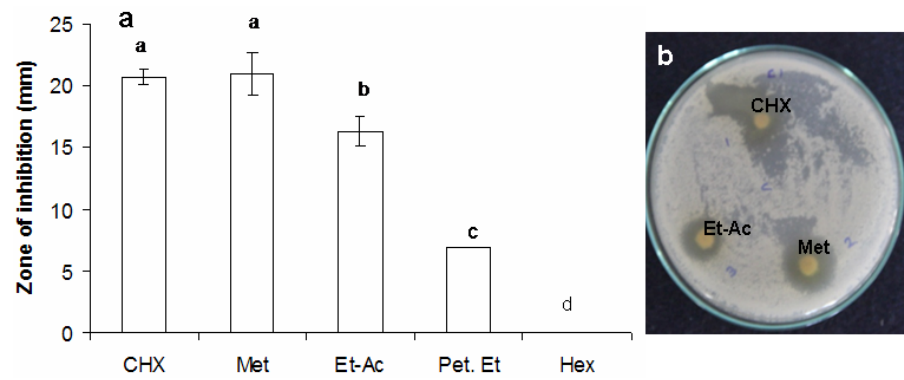

Figure 2: Anti-candidal activity of Garcinia imberti bourd leaf extracts against multidrug resistant $\mathrm{C}$. albicans (Ca-09). a) CHX-chlorohexidine (Control), Met - methanol fraction, Et-Ac - ethyl acetate fraction, Pet.Et - Petroleum ether fraction, and Hex - hexane fraction. b) Plate showing anti candidal activity of the Garcinia imberti bourd leaf extract. Bar showing different superscript has significantly different $(P<0.05)$ Tukey HSD test.

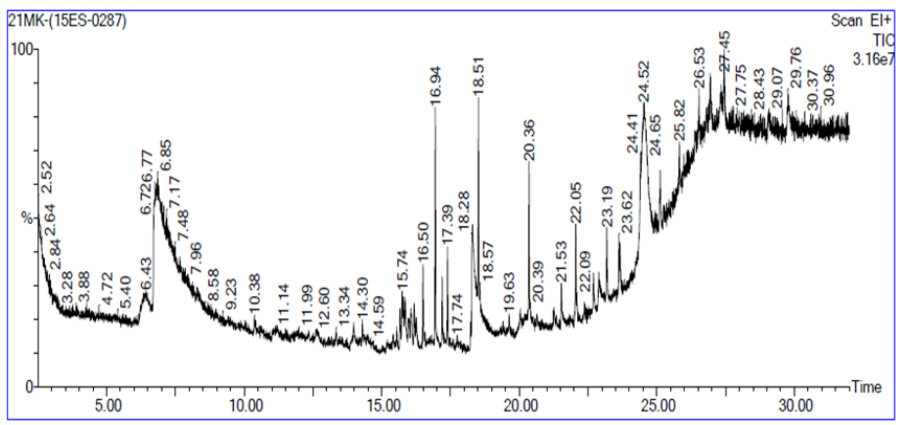

Figure 3: GC-MS spectrum of partially purified compound from methanol extract (F21 fraction of column chromatography) of Garcinia imberti bourd leaf.

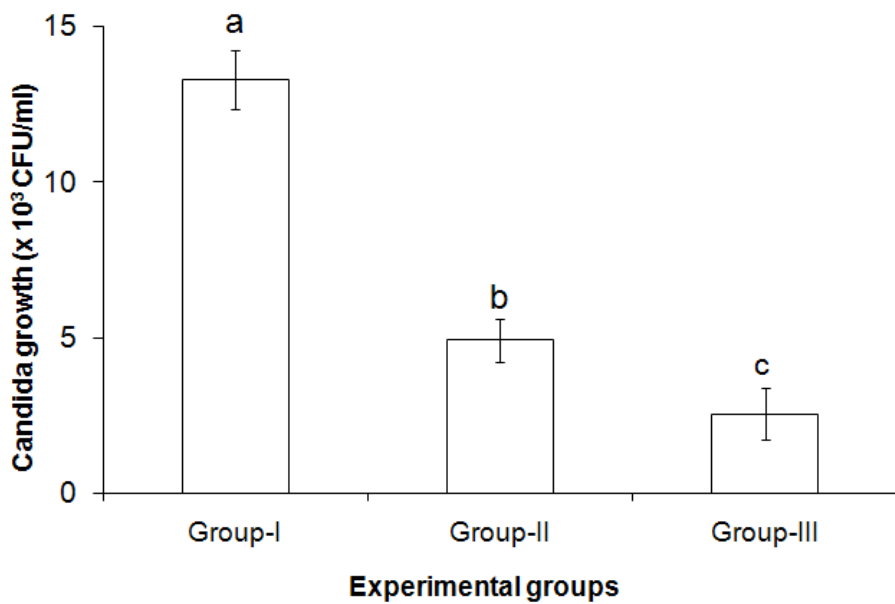

Figure 4: Intracanal medicament activity of methanol extract of Garcinia imberti bourd leaf in decoranated teeth. GROUP I (control; Neutral gel) normal saline with $1 \mathrm{~g}$ of $2 \%$ methyl cellulose; GROUP-II, $0.01 \mathrm{~g}$ of a methanolic extract with $2 \%$ methyl cellulose gel; GROUP- III: $20 \mu \mathrm{l}$ of $2 \%$ chlorohexidine with $2 \%$ methyl cellulose gel. After 21 days of incubation the viable count was enumerated by standard plate count method on SDA. Bar showing different superscript has significantly different $(P<0.05)$ Tukey HSD test.

\section{Table 2: Bioactive compounds detected by GC-MS method from the} F21 fraction of methanol extract of G. imberti bourd

\begin{tabular}{|c|c|c|c|}
\hline S.No. & Rt value & Area (\%) & Compounds \\
\hline 1 & 6.85 & 35.541 & Glycerine \\
\hline 2 & 16.94 & 5.98 & $\begin{array}{c}\text { 3,7,11,15-Tetramethyl-2-Hexadecen- } \\
1 \text {-oL }\end{array}$ \\
\hline 3 & 18.300 & 8.66 & N-Hexadecacoic acid \\
\hline 4 & 18.51 & 3.987 & 1-Decosene \\
\hline 5 & 20.36 & 4.574 & 1-Decosene \\
\hline 6 & 24.41 & 3.34 & $\begin{array}{c}3,7,11,15 \text { Tetra methyl }-12 \text { Hexadecen } \\
1-\mathrm{oL}\end{array}$ \\
\hline 7 & 24.54 & 30.43 & $\begin{array}{l}\text { 3-Butoxy 1,1,1,5,5,5 Hexamethyl -3- } \\
\text { (Trimethyl Siloxy) Trisiloxane }\end{array}$ \\
\hline
\end{tabular}

(Figure 4). The extract showed better inhibitory action towards C. albicans, overall $63 \%$ of the C. albicans were reduced, besides, chlorohexidine was more effective ( $81 \%$ inhibition) than the methanol extract. Similar findings were reported by previous works done. ${ }^{13}$ Although many experiments have been carried out in detecting the efficacy of herbal extracts against the microbes in associated with root canal infection, ${ }^{24}$ the efficacy of the G. imberti bourd towards C. albicans in associated with root canal infection is highlighted first through this study.

\section{CONCLUSION}

As the methanolic extract of Garcinia imberti bourd was found superior in activity against $C$. albicans. It seems to be the potential candidate for an anticandidal agent. GC-MS analysis of the methanol extract showed glycerein, one of the major compound, which could be used as an active ingredient in making suitable herbal intracanal medicament for the root canal treatment. 


\section{ACKNOWLEDGEMENT}

Authors are thankful to Dr. Sathish Gopal Dhas, Principal, White Memorial College of Physiotherapy, Dr. P. Vijayaraghavan, Director, Zyme Biotech, Nagercoil for their encouragement.

\section{CONFLICT OF INTEREST}

The authors declare no conflict of interest.

\section{ABBREVIATION USED}

CHX: Chlorohexidine; NaOCl: Sodium hypochlorite; GCMS: Gas Chromatography Mass Spectroscopy; SDA: Sabourad Dextrose Agar.

\section{REFERENCE}

1. Brook I, Frazier E, Gher M. Aerobic and anaerobic microbiology of periapical abscesses. Oral Microbial Immunol. 1991;6(2):123-5.

2. Siqueira JF Jr, Rocas IN, Lopes HP, Elias CN, de Uzeda M. Fungal infection of the radicular dentin. J Endod. 2002;28:770-773.

3. Cohen S, Burns RC. Pathways of the pulp $6^{\text {th }}$ edn. St Louis: Mosby, 1994; 216:337-340.

4. Waltimo TMT, Haapasalo M, Zehnderd M, Meyer J. Clinical aspects related to endodontic yeast infections. Endodont Topic. 2004;9(1):66-78.

5. Sullivan DJ, Moram GP, Pinjon E, Al-Mosaid A, Strokes C, Vaughan C, Coleman DC. Comparison of the epidemiology, drug resistance mechanisms and virulence of Candida dubliniensis and Candida albicans. FEMS Yeast Res. 2004;4(4-5):369-76.

6. Hulsmann M, Hahn W. Complications during root canal irrigation-literature review and case reports. Int Endodont J. 2000;33(3):186-93.

7. Narayanan L, Vaishnavi C. Endodontic microbiology (invited review). J Conserv Dent. 2010;13(4):233-9.

8. Vinothkumar TS, Rubin MI, Balaji L, Kandaswamy D. In vitro evolution of five different herbal extracts as an anti microbial endodontic irrigant using real time quantitative polymerase chain reaction. J Conser Dent. 2013;16(2):167-70.

9. Fouad AF, Barry J, Caimano M, Clawson M, Zhu Q, Carver R, et al. PCR based identification of bacteria associated with endodontic infection. J Clin Microbiol. 2002;40(9):3223-3231.

10. Hossain MA, Al Hdhrami SS, Nasser J. Isolation, fractination and identification of chemical constituent from leave crude extract of Mentha pipertia L.grown in
Sultanate of Oman. Asian Pac J Trop Biomed. 2014;4(11):368-72.

11. Samyal ML, Ahya A, Ahmad Z. Evaluation of antidiabetic activity of isolated compound from Ougenia ojeinesus bark extract in rats. UK J Pharma Biosci. 2014;2(5):27-33.

12. Rajeshwari G, Murugan M, Mohan VR. GC-MS analysis of bioactive components of Hugonia mystax L. (Linaceae). Res J Pharm Biol Chem Sci. 2012;3(4):301-8.

13. Mozayeni MA, Hadian A, Bakhshaei P, Dianat O. Comparison of antifungal activity of $2 \%$ chlorohexidine, calcium hydroxide and nano-silver gel against Candida albicans. J Dent (Tehran). 2015;12(2);109-12.

14. Segura-Egea JJ, Castellanes-Cosano L, Machuca G, Lopez-Lopez J, MartinGonzalez J, et al, Dominguez Francisco BS. Diabetes mellitus periapical inflammation and endodontic treatment outcome. Med Oral Patol Oral Cir Bucal. 2012:17(2):356-61.

15. Kumar J, Sharma R, Sharma M, Prabhavathi V, Paul J, Chowdary CD. Presence of Candida albicans in root canals of teeth with apical periodontitis and evaluation of their possible role in failure of endodontic treatment. J Int Oral Health. 2015;7(2):42-5.

16. Waltimo T, Luo G, Samaranayaka LP, Vallitu PK. Adherence of Candida albicans to a new fiber reinforced polymer enriched with chlorohexidine digluconate. J Matter Sci Matter Med. 2003;15:117-21.

17. Lopez J, Pernot C, Aho S, Caillot D, Vagner O, Dalle F, et al. Decrease in Candida albicans strains with reduced susceptibility to Fluconazole following changes in prescribing policies. J Hosp Infect. 2001;48(2):122-8.

18. Dhanasekaran D, Vinothini K, Latha S, Thajuddin N, Panneerselvam A. 2014 Human dental biofilm: screening, characterization, in vitro biofilm formation and antifungal resistance of Candida spp. Saudi J Den Res. 2014;5(1):55-70.

19. Elie CM, Lott JJ, Reisse Morrism CJ. Rapid Identification of Candida species with species specific DNA probes. J Clin Microbiol. 1998;36(11):3260-5.

20. Jackson DN, Yang L, Wu S, Kennelly EJ, Lipke P. Garcinia xanthochymus Benzophenones promote hyphal apoptosis and potentiate activity of fluconazole against Candida albicans biofilms. Antimicrob Agents Chemother. 2015; 59(10):6032-8.

21. Nagendra K, Husum $H$, Ramachandran HD. Anti microbial, antifungal and anti oxidant activity of ethanolic extracts of Garcinia indica Fruit. Int J Curr Microbiol App Sci. 2014;3(9):800-4.

22. Sharanappa R, Vidyasagar GM. Anti candida activity of medicinal plants. A Review Jnt Pharm Pharmaceut Sci. 2013:(5)4:9-16.

23. Nalawade TM, Bhat K, Sogi SHP. Bacterial activity of propylene glycol, glucerine polyethylene 400 and polyglycol 1000 against selected micro organism. J Int Soc Prev Commu Dent. 2015;5(2):114-9.

24. Elegandy AA, Nagy MM. The effect of different intracanal medication on fricative resistance of root canal dentin. Tanta Dent J. 2015;12(3):163-7.

Article History: Submission Date: 07-11-16; Received Date: 27-01-17; Acceptance Date: 14-02-17.

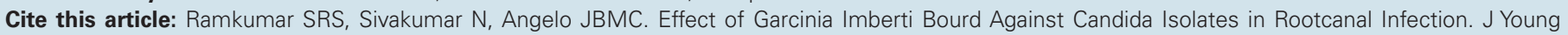
Pharm. 2017;9(2):214-7. 